\title{
Sistema Tributario y el Problema Federativo: la Evolución del Caso Brasileño
}

\begin{abstract}
Amaury Patrick Gremaud ${ }^{1}$
\section{Resumen}

El presente artículo tiene por objetivo caracterizar la evolución de los aspectos tributarios de las relaciones intergubernamentales brasileñas. Buscando establecer taxonomías relativas tanto a las distintas posibilidades de evolución histórica de la estructura federativa de diferentes países, como a las posibilidades de distribución de los ingresos. Considerando básicamente, el período republicano (1889 - 2000) y específicamente las alteraciones constitucionales de este período.
\end{abstract}

Palabras-clave: Sistema tributario; problema federativo; relaciones intergubernamentales brasileñas; período republicano (1889 - 2000).

\section{Resumo}

O presente artigo tem por objetivo caracterizar a evolução dos aspectos tributários das relações intergovernamentais brasileiras. Procurando estabelecer taxonomias relativas tanto às distintas possibilidades de evolução histórica da estrutura federativa dos diferentes países, como para possibilidades de distribuição da renda. Considerando principalmente, o período republicano $(1889$ - 2000) e e principalmente, as alterações constitucionais neste período.

Palavras-clave: Sistema tributário; problema federativo; relações intergovernamentais brasileiras; período republicano (1889 - 2000).

\section{Introducción}

Cuando se observa la historia de la formación de las estructuras federativas de muchos Estados Nacionales percibimos que la misma asume distintos movimientos. Por un lado, existen países como los Estados Unidos o Suiza, en los cuales la federación se originó de la agregación voluntaria de sus partes constituyentes. Las "13 colonias norteamericanas" fueron las que buscaron un acuerdo para constituir un nivel jerárquico superior, confiriéndole una unión - los Estados Unidos de Norteamérica -. Suiza nace también de la unión de tres cantones, en la época, partes de los señoríos o dominios que acabaron por sublevarse de las relaciones de soberanía dominantes, creando una entidad aparte - la Confederación Helvética -. Con el pasar del tiempo, otros cantones se agregaron configurando así la Suiza actual. Estos países nacieron

\footnotetext{
${ }^{1}$ Profesor del Programa de Pós-graduação em Integração da América Latina da Universidade de São Paulo PROLAM/USP y FEARP/USP, e-mail: agremaud@usp.br
} 
descentralizados y buscaron, paulatinamente, una mayor centralización. El problema, en estos casos, es saber cómo mantener mismamente la autonomía de las regiones y, al mismo tiempo, obtener las ventajas de un mayor grado de centralización. El mismo caso, mutatis mutandi, se aplica a la historia reciente de la Unión Europea. Usando la expresión de Stepan (1999), éstas son las "coming together federations".

Es diferente, la experiencia de la mayor parte de los países en desarrollo que heredaron estructuras centralizadas - "holding together federations" -. Con el pasar del tiempo esta centralización sufrió una ruptura; tal ruptura, sin embargo, asumió dos formas. En primer lugar, la descentralización como consecuencia de batallas internas contra el Estado centralizado, que acabaron aceptando tales soluciones descentralizadoras, algunas veces, por ejemplo, con el objetivo de impedir luchas separatistas. La descentralización, en estos casos, fue una conquista arrancada de las manos de los gobiernos centrales: habiendo, de este modo, una descentralización por demanda. Otras veces, la estrategia de descentralización fue una imposición del propio gobierno central sobre las instancias subnacionales, que acabaron por someterlas. Aquí la descentralización no fue una decisión autónoma de los gobiernos subnacionales: en este caso hubo una descentralización por oferta. En estos últimos casos el análisis debe realizarse de manera más atenta para no confundir una efectiva descentralización con la imposición de medidas de desconcentración, en la que se amplía la actividad de las jurisdicciones jerárquicamente inferiores en la condición de "oficinas regionales" de los gobiernos centrales. Transfiriéndose atribuciones y no responsabilidades y mucho menos poder. No se debe confundir los casos de descentralización y desconcentración. ${ }^{2}$ Estableciéndose, desde entonces, para los procesos históricos en los que las federaciones están involucradas la siguiente tipología:

a) Una que busca el fortalecimiento de la Unión.

b) Otra que busca el fortalecimiento de los entes subnacionales.

En este último caso hay dos posibilidades:

b.1) La descentralización por demanda.

\footnotetext{
2 A respecto de estos conceptos y las ventajas y desventajas de la descentralización ver, por ejemplo, Bahl (2001), Gremaud (2001) o, incluso distintos artículos contenidos en Affonso\& Silva (1995).
} 


\section{b.2) La descentralización por oferta.}

La duda de cuál es la mejor forma de dirigir un país con sus dimensiones territoriales, en el caso brasileño, no es reciente. Desde inicios de la fase colonial, se alternaran experiencias como las de las "Capitanías Hereditarias" (1530) y del "Gobierno General" (1549). Las evaluaciones sobre la experiencia brasileña, destacaran en el último sesquicentenario, la metáfora del péndulo paretiano en que se alternaran épocas de centralización con periodos de descentralización. A la fase imperial (1822 - 1889), época de gran centralización ${ }^{3}$, sucederá la Primera República (1889 - 1930) caracterizada por una fuerte descentralización. Otra característica señalada, a lo largo de este siglo, es la relación entre la centralización y los períodos autoritarios, mientras que las tendencias descentralizadoras se asociaran a los períodos de fortalecimiento democrático.

En este sentido, en el período post II Guerra Mundial, en oposición al régimen autoritario impuesto por Getúlio Vargas durante el "Estado Novo" (1937 -1945), se iniciará una época de descentralización, que a comienzos de la década del 60 asumirá proporciones significativas revertida posteriormente, por el golpe militar de 1964. La dictadura militar (1964 - 1984) marcará una fuerte centralización; la Unión y las empresas estatales federales dominaran gran parte de los recursos públicos y controlaran de cerca la economía brasileña. A finales de los años 70, habrá una mayor descentralización, que culminará con la Constitución de 1988. El aumento del poder y de la autonomía política de los gobiernos subnacionales será, por lo tanto, uno de los aspectos que asumirá el movimiento de redemocratización. ${ }^{4}$

Aunque las reivindicaciones descentralizadoras hayan sido exitosas en algunos momentos, la tradición hizo que el péndulo se orientase más para el lado centralizador. En este sentido vale la observación de Kugelmas \& Sola (1999, 63 y 64):

\section{"La tan seductora metáfora (...), que se origina en el pensamiento de Wilfredo} Pareto, es excesivamente simplista y puede conducir a equívocos. Restando en las

\footnotetext{
${ }^{3}$ A comienzos del Imperio, estas mismas reivindicaciones centralizadoras y después separatistas, se mostraron especialmente fuertes durante la fase de la regencia, pero fueron aplacadas. Sobre el Federalismo brasileño en el período imperial Carvalho (1993).

${ }^{4}$ Esta relación entre descentralización y redemocratización también es considerada en otros países de América latina por Burki, Perry \& Dillinger (1999).
} 
sombras algunos aspectos de continuidad en estos procesos, que son esenciales para la comprensión de la evolución del régimen federativo y de la oscilación entre centralización y descentralización. (...) La célebre metáfora nos puede inducir a la creencia de una anulación completa de los mecanismos institucionales anteriores a cada movimiento pendular, cuando lo que de hecho ocurre es una modificación del patrón de relación entre las esferas, a través de una dinámica de apretar/aflojar los controles políticos y fiscales. Resulta de peculiar relevancia resaltar estos aspectos para un análisis de la rica y compleja coyuntura reciente, donde convergen aspectos recentralizadores y descentralizadores. Por eso la necesidad de superar la útil pero insuficiente idea de alternancia de momentos de centralización y de descentralización, buscando los contextos políticos e institucionales de la actuación de los principales actores involucrados y permaneciendo atentos a las manifestaciones de path dependence."

En Brasil se configuró, en las últimas décadas, un cuadro originalmente de descentralización por demanda. Según Affonso \& Lobo (1996, 10):

"La descentralización no nace de una acción de la política fiscal o económica, nace de una reacción de los gobiernos subnacionales o a favor de éstos, contra los poderes dichos excesivos del centro."

No hubo específicamente una redefinición de funciones y atribuciones, sino que fue un proceso intrincado, que resultó en un aumento de la importancia de los poderes subnacionales, a lo largo de los años 1970 y en especial de los 1980. Al inicio, el aumento de la importancia ocurrió principalmente desde el punto de vista del ingreso y más recientemente, de un modo pausado, también se verificó desde el punto de vista de las atribuciones. La descentralización acompañó una agenda política conflictiva, que fue objeto de grandes negociaciones políticas. Esta agenda política presentó un curso desordenado y configuró una serie de problemas, desequilibrios y resultados hasta ahora bastante desiguales. Aún cuando el gobierno federal intentó organizar la descentralización, la motivación no fue buscar los beneficios de la misma pero configuró un orden financiero más adecuado, solucionando específicamente los asuntos fiscales del Estado como un todo. 
En la década de los noventa y en los primeros meses del nuevo siglo, debido a los desequilibrios del proceso y de las dificultades, como el ajuste macroeconómico del país, se produjieron muchas alteraciones en el cuadro de las relaciones intergubernamentales. En algunos puntos significó un retroceso en el proceso de descentralización, como por ejemplo: el recién crecimiento de la recaudación federal (con base en impuestos de calidad dudosa), el Fondo de Estabilización Fiscal $^{5}$, las renegociaciones de deudas provinciales y municipales, las acciones sobre los bancos provinciales y la Ley de Responsabilidad Fiscal ${ }^{6}$, retirando autonomía de las esferas subnacionales. La justificativa para el retroceso fueron las dificultades macroeconómicas del proceso de estabilización. Por otro lado, especialmente del lado de las atribuciones y de la política social, se han efectuado varios avances en términos de descentralización. Poco a poco se fueron resolviendo muchas indefiniciones. Estos avances no se producen de igual forma a lo largo de todo el territorio, mostrando las dificultades horizontales del federalismo brasileño.

De esta manera, actualmente se vive un momento de importantes definiciones desde el punto de vista federativo. Tanto las fuerzas descentralizadoras como las recentralizadoras están en operación. Las posibilidades abiertas apuntan hacia algunas direcciones posibles que son:

a) El vuelco de esta descentralización, que puede ser:

a.1) recentralización, con el gobierno federal reasumiendo atribuciones y sobre todo participación en las recaudaciones;

a.2) la transformación de la descentralización en desconcentración, manteniendo las atribuciones locales con sus respectivas recaudaciones, pero sin que los gobiernos locales tengan efectivamente poder en la definición de estas atribuciones e ingresos, o sea, los entes subnacionales realizan funciones definidas y establecidas por el gobierno federal sin ninguna autonomia, incrementando fuertemente sus ingresos con transferencias condicionadas recibidas de la Unión;

b) La readecuación del sistema federativo, que puede:

\footnotetext{
${ }^{5}$ El Fondo es, en parte, una retención de las transferencias constitucionales que se hacían a las provincias y a los municipios.

${ }^{6}$ La Ley impone reglas para los presupuestos de los gobiernos subnacionales
} 
b.1) seguir el camino del federalismo competitivo, en que se separan atribuciones entre los distintos niveles federativos donde, desde el punto de vista horizontal, cada una de las unidades actúa individualmente;

b.2) o buscar un federalismo cooperativo, en que se comparten las funciones e ingresos y especialmente decisiones entre las diferentes unidades federativas, tanto desde el punto de vista horizontal como vertical.

Cada una de estas opciones, compromete la forma en que se reparten las diferentes atribuciones, el ingreso de tasas e impuestos y también la posibilidad y las reglas del endeudamiento subnacional. En lo adelante profundizaremos esta discusión restringiéndonos a la cuestión de la distribución de los ingresos.

\section{Algunas Consideraciones sobre la Responsabilidad de Tributar en una Federación $^{7}$}

Acerca de las posibilidades de la distribución de competencias tributarias, la cuestión más debatida es la referente a los diferentes tipos de tributos - sobre la renta (ingreso), el consumo, la riqueza, etc. - y su asignación a los distintos niveles de gobierno. En general, los impuestos, cuando son recogidos localmente, tienden a generar distorsiones e ineficiencias. Así, resta a las esferas locales: los tributos sobre factores inmuebles (tierra y propiedad inmobiliaria) y tasas relacionadas con determinados servicios públicos. Estas formas de recaudación no generan recursos suficientes, así es necesario crear algún sistema de transferencia entre las esferas central y locales. ${ }^{8}$

Sin embargo, la distribución de los ingresos puede verse de una forma más completa, si se toman en consideración diferentes combinaciones de los elementos siguientes:

\footnotetext{
${ }^{7}$ Las consideraciones que se hacen en este tópico se basan en Moraes (2001), especialmente, páginas. 106 a 114.

${ }^{8}$ Este punto es obviamente bastante complejo y merece un espacio más amplio. Para una discusión actual ver TerMinassian (1997) y especialmente BIRD (1999), que revisa las posiciones clásicas, como la de la antipatía a la atribución de los impuestos sobre el valor agregado a niveles subnacionales.
} 
- la responsabilidad política sobre los tributos, o sea, la decisión de tributar algo y su proporción (¿quién define la legislación sobre la base donde recaen los impuestos y la estructura de alícuotas?),

- la responsabilidad administrativa sobre los tributos (sistema de recaudación o estructura recaudativa) y

- $\quad$ la disponibilidad de los recursos recaudados (¿quién se queda con lo recaudado?).

En este sentido hay varios sistemas posibles respecto a la distribución de competencias tributarias en un país federativo.

Inicialmente, podemos apuntar para los sistemas autónomos, en los que se asignan las responsabilidades tributarias por la división de tributos. Por lo general, las responsabilidades políticas, administrativas y los propios recursos de cada tipo de impuestos están en una misma esfera administrativa. Dentro de este sistema existen dos modelos:

a) en una situación extrema, la autonomía tributaria completa de los entes de la federación, en la que cada uno puede elegir sus fuentes tributarias, determinar las bases y las alícuotas; además de administrar y recolectar los ingresos resultantes y

b) en un modelo más realista, la separación de tributos, en el cual se definen, por lo general constitucionalmente, los tributos proprios a cada uno de los niveles de gobierno y cada uno de estes poseerá completa autonomía (política, administrativa y sobre la recolección de sus ingresos).

En estos modelos, los gobiernos locales tienen autonomía para definir el tamaño de su presupuesto y su propia política fiscal. ${ }^{9}$ Sin embargo, los problemas son evidentes: la gran complejidad del sistema tributario, la falta de coordinación y especialmente, en el caso de la autonomía completa, la duplicación de esfuerzos. De este modo, existirán dificultades especialmente con relación a las funciones estabilizadoras y distributivas del Estado. ${ }^{10}$

\footnotetext{
${ }^{9}$ Siempre que, en caso de separación de fuentes, sean atribuidas fuentes tributarias que efectivamente posibiliten un ingreso razonable a cada uno de los entes de la federación.

${ }^{10}$ Ver Musgrave \& Musgrave (1973) que definen las funciones del Estado en tres órdenes: asignación, estabilización y distribución.
} 
En el otro extremo están los sistemas centralizados. En éstos, especialmente las responsabilidades políticas sobre los impuestos son centralizadas, a pesar de que los recaudos son divididos entre los diferentes niveles de gobierno. En este caso podemos tener modelos basados en:

c) la restribución de ingreso por transferencias, en que un ente - por lo general el central - es responsable por la definición de los tributos y su recaudación, los que serán redistribuidos a los otros entes subnacionales a través de transferencias. Estos, a su vez, pueden ser generales, definidos por fórmulas o condicionados para determinados tipos de gasto, o aún, completamente ad hoc (en este caso, su subdivisión quedará totalmente a criterio del ente recaudador).

d) otra posibilidad es la división de competencias tributarias, donde el gobierno central retiene la competencia política definiendo los principales aspectos relativos a los tributos (especialmente los relativos a la base y a las alícuotas), pero la administración y principalmente, el recaudo, es de responsabilidade de los entes subnacionales. ${ }^{11}$

Por el hecho de existir dificultades en definir el propio tamaño de la intervención pública subnacional, pues el tamaño del presupuesto no es, ni en parte, definido en términos subnacionales, tenemos, en estos casos, una importante pérdida de la autonomía de los gobiernos subnacionales, dificultando la obtención de algunos de los elementos considerados esenciales para un estado descentralizado. Estos elementos son: la responsabilidad de los gobernantes locales ante los ciudadanos de su jurisdicción ${ }^{12}$ y la efectiva posibilidad de adecuar las preferencias de los ciudadanos a la oferta de los bienes públicos;. Por otro lado, la posibilidad del control macroeconómico de las autoridades federales aumenta mucho con estos sistemas. ${ }^{13}$. En el

\footnotetext{
${ }^{11}$ Las recaudaciones, en un caso límite, pueden quedar enteramente en manos de un gobierno subnacional mientras que las reglas tributarias son definidas por el gobierno central. Mas existe la posibilidad de que se instituya alguna regla que divida los ingresos. En Brasil un ejemplo es el impuesto territorial rural (ITR), definido en el ámbito federal aunque el total recaudado se reparte al 50\% entre la Unión y las municipalidades. Dependiendo del sistema de transferencias establecido en el modelo anterior y la regla de subdivisión de las recaudaciones; los dos modelos presentados dentro del sistema centralizado pueden aproximarse.

12 Éstos pueden siempre alegar que no se les ofrece determinados tipos de bienes porque no poseen los recursos suficientes. En realidad, la propia responsabilidad de los ciudadanos locales en términos de demanda y financiamiento de los bienes públicos locales está dificultada, porque estas transferencias no siempre están claras.

${ }^{13}$ Aún así, por lo general existen reclamaciones de los gobiernos centrales cuando la división de lo recaudado es inflexible.
} 
caso de la redistribución de lo recaudado con base en las transferencias, existe también la posibilidad de promover con más facilidad la redistribución regional de los recursos.

Ante estos dos sistemas básicos surgen los sistemas intermediarios, en los cuales se preserva alguna autonomía de decisión del gobierno subnacional, al mismo tiempo en que se busca mantener algún grado de homogeneidad del sistema tributario. En este caso tenemos:

e) el modelo de compartimiento de tributos. El gobierno central define la base y los principales aspectos administrativos del impuesto. Éste definirá también, su propia alícuota en cuanto los gobiernos subnacionales definirán, por ejemplo, sobrealícuotas que les producirán ingresos. Las alícuotas de los otros entes, pueden limitarse estableciendo pisos y/o techos, dentro de los cuales pueden libremente ubicarse las diferentes jurisdicciones.

Por este sistema, existe una reducción de parte de los problemas administrativos y de coordinación, que ocurren en los sistemas autónomos, manteniendo sus elementos básicos: la definición sobre el ingreso marginal y la posibilidad de determinación, por lo menos en parte, del tamaño del presupuesto subnacional. No obstante, si no existe autonomía subnacional total, la homogenización del sistema tampoco ocurre completamente, restando, por ejemplo, la posibilidad de prácticas que lleven a la competencia o "guerra fiscal" entre los gobiernos subnacionales.

Con relación a estas prácticas (guerras fiscales), aunque las mismas traen desventajas ${ }^{14}$, si ciertos elementos están presentes, también pueden obtenerse algunas ventajas, tales como: incentivos en el sentido de imponer una carga fiscal adecuada - más próxima de la requerida por las necesidades y los intereses de los ciudadanos; posibilidad de resultados benéficos resultantes de experiencias tributarias innovadoras y agilidad al adecuar la tributación ante los cambios en la economía.

Los principales elementos para frenar los maleficios de la "guerra fiscal" son: i) la existencia de restricciones presupuestarias rígidas, en el sentido de que quien quiera hacer guerra fiscal, lo haga exclusivamente con sus recursos y ii) un sistema político que otorgue efectiva responsabilidad a los administradores por sus actos. No resulta fácil construir estos dos elementos

\footnotetext{
${ }^{14}$ Ver Viol (2000) o Prado \& Cavalcanti (2000).
} 
de forma institucional pero, al mismo tiempo, son fundamentales, si existe interés en evitar sistemas tributarios excesivamente centralizados y en preservar alguna autonomía tributaria subnacional, como en el caso de los sistemas intermediarios.

Probablemente ningún país utiliza in totum ninguno de estos modelos ya que el sistema tributario es una combinación de sistemas. Entre tanto, la supremacía de un sistema u otro es un elemento importante en la caracterización del sistema federativo del país.

\section{Breve descripción de la evolución del sistema tributario brasileño ${ }^{15}$}

La estructura de recaudaciones en Brasil, estuvo históricamente relacionada con el comercio externo, en función de la facilidad de cobranza y al mismo tiempo, de las propias características de la economía brasileña, por lo menos, hasta el fin de la Primera República (1930). El impuesto de importación fue la base de los ingresos gubernamentales (tabla 1). La segunda fuente de ingreso del gobierno imperial (1822 - 1889) fue el impuesto sobre las exportaciones. De manera contradictoria, este impuesto fue raro ya que recaía sobre uno de los sectores políticamente más fuertes del país, durante este período. No obstante, los tributos aduaneros eran fácilmente cobrados y recaían sobre los sectores más dinámicos de la economía. Otros, como el impuesto sobre la propiedad rural y el impuesto sobre los ingresos (renta), eran de difícil recaudación y también sufrían una fuerte oposición política. ${ }^{16}$

Tabla 1: Brasil Imperial: Principales Fuentes de Ingresos Fiscales. En porcentaje sobre el total Años Seleccionados

\begin{tabular}{lccc}
\hline \multicolumn{1}{c}{ Tipos de Ingreso Recaudados } & $1869 / 70$ & $1878 / 79$ & 1889 \\
\hline Impuesto sobre Importación & 55,2 & 53,0 & 56,0 \\
Impuesto sobre Exportación & 18,8 & 16,0 & 11,0 \\
Ingresos Aduaneros (Total) & $\mathbf{7 5 , 0}$ & $\mathbf{6 9 , 0}$ & $\mathbf{6 7 , 0}$ \\
Impuesto sobre Transacción de Propiedades & 4,0 & 4,2 & 3,8
\end{tabular}

\footnotetext{
${ }^{15}$ Existen varias referencias importantes sobre la evolución del sistema tributario brasileño, esta sección se basa en Varsano (1997), Amed \& Negreiros (2000), Cunha (1995) \& Silva \& Beres (1990).

${ }^{16}$ Debemos observar que en el país había, cuando ocurre la Declaración de la Independencia, un número bastante grande de impuestos, pero el valor total de su recaudación era bajo.
} 


$\begin{array}{llll}\text { Impuesto al Sello } & 3,6 & 3,4 & 3,5 \\ \text { Impuesto de Industrias y Profesiones } & 3,2 & 3,0 & 3,0 \\ \text { Impuesto Predial } & 1,8 & 2,8 & 2,3\end{array}$

Fuente: Datos recopilados en Deveza (1995).

El Imperio brasileño tenía también características fuertemente centralizadoras ${ }^{17}$, a pesar de una ligera tendencia a la caída de esta centralización al fin del período, como observamos seguidamente en la tabla 2.

Tabla 2: Brasil y Otros Países: Ingreso por Nivel de Gobierno. En porcentaje sobre el total Años Seleccionados.

\begin{tabular}{ccccc}
\hline Nivel & E.U.A & México & Brasil & $\begin{array}{c}\text { Brasil } \\
(1902)\end{array}$ \\
\hline Federal & 37,1 & 63,0 & 83,1 & 76,8 \\
Provincial & 10,9 & 24,1 & 14,0 & 18,2 \\
Local & 52,0 & 12,9 & 2,7 & 5,0 \\
\hline
\end{tabular}

Fuente: Datos recopilados de Carvalho (1986).

Las reivindicaciones descentralizadoras ganaron fuerza durante el movimiento republicano. Efectivamente, una vez proclamada la República (1889), a pesar de conservarse buena parte de la estructura tributaria imperial, el nuevo sistema de gobierno adquierió características nítidamente federativas. Dándoles mayor autonomía a las Provincias y facultándolas para el acceso al mercado de crédito, transfiriendo atribuciones y, principalmente, tributos - el impuesto de exportación se transfirió a las provincias. ${ }^{18}$

La Constitución de 1891 designó, de forma más clara, los tributos que le competen a cada uno de los distintos niveles de gobierno, adoptando el régimen de separación de tributos. Las Provincias, fueron obligadas a establecer leyes que definieron los impuestos municipales con el

\footnotetext{
${ }^{17}$ Sobre el federalismo brasileño en su fase imperial, ver Carvalho (1993).

${ }^{18}$ Un aspecto interesante es que el impuesto sobre exportación recaía no solamente sobre las exportaciones a otros países, sino también a otras provincias miembros de la federación.
} 
fin de que éstos pudieran cumplir sus funciones. ${ }^{19}$ Los principales impuestos en este caso eran el impuesto sobre edificaciones y también sobre industrias y profesiones.

A lo largo de la Primera República se crearon nuevos impuestos y/o se dinamizaron antiguos. Se crearon los impuestos sobre consumo ${ }^{20}$, sobre ventas mercantiles ${ }^{21}$ y el impuesto a la renta general. ${ }^{22}$ A pesar de los cambios, la base de la recaudación estaba formada aún por las tarifas aduaneras (tabla 3). ${ }^{23}$ En las Provincias, el Impuesto de Exportación representó un 38\% del ingreso, seguido del impuesto de transacción (un 8,4\%) y el de industrias y profesiones (un $5 \%)$.

Tabla 3: Brasil: Participación de los Principales Impuestos en la Esfera Federal. En porcentaje sobre el total $(1889-1965)$

\begin{tabular}{lccc}
\hline & $\begin{array}{c}\text { Impuesto de } \\
\text { Importación }\end{array}$ & $\begin{array}{c}\text { Impuesto sobre } \\
\text { Consumo }\end{array}$ & $\begin{array}{c}\text { Impuestos sobre } \\
\text { los Ingresos }\end{array}$ \\
\hline $1889-1914$ & $54,97 \%$ & $10,02 \%$ & $1,49 \%$ \\
$1915-1919$ & $33,59 \%$ & $19,33 \%$ & $4,24 \%$ \\
$1920-1930$ & $37,58 \%$ & $19,24 \%$ & $2,67 \%$ \\
$1931-1937$ & $33,77 \%$ & $20,66 \%$ & $5,99 \%$ \\
$1938-1945$ & $19,36 \%$ & $27,66 \%$ & $17,96 \%$ \\
$1946-1950$ & $10,89 \%$ & $32,47 \%$ & $26,31 \%$ \\
$1950-1955$ & $6,26 \%$ & $30,25 \%$ & $32,20 \%$ \\
$1956-1960$ & $7,68 \%$ & $34,01 \%$ & $30,36 \%$
\end{tabular}

\footnotetext{
${ }^{19}$ Además de estos impuestos principales había una serie de otros impuestos residuales. La Constitución permitía también a la Unión y a las Provincias el poder de crear nuevos tributos.

${ }^{20}$ Antes de éste ya existían impuestos sobre el tabaco (1892) y sobre el alcohol (1772)

${ }^{21}$ Creado en 1922 originará el impuesto sobre ventas y consignaciones.

22 Creado en 1923, empieza a recaudarse en 1924, pero antes había una serie de impuestos sobre ingresos específicas como dividendos (1892), vencimientos (1892), intereses del título de crédito (1914), ganancias empresariales (1920) y de profesionales liberales (1921).

${ }^{23}$ Durante la I Guerra Mundial, los impuestos sobre algunos tipos de ingreso y sobre el consumo aumentaron y el de importación cayó. Después de la Guerra y retomado el flujo normal de comercio internacional, el impuesto de importación volvió a crecer, pero con participación inferior al de antes de la guerra.
} 

$1960-1965$
$8,75 \%$
$40,30 \%$
$26,00 \%$

Fuente: Datos básicos en Varsano (1997). 


\section{Cuadro 1:}

\begin{tabular}{|c|c|c|c|c|c|c|c|}
\hline \multicolumn{8}{|c|}{ Evolución de la Competencia tributaria en las Constituciones Brasileñas (1891-1988) } \\
\hline \multirow{2}{*}{ Tributos y Competencias } & \multicolumn{7}{|c|}{ Constituciones } \\
\hline & 1891 & 1934 & 1937 & 1946 & 1967 & 1969 & 1988 \\
\hline \multicolumn{8}{|l|}{ De la Unión } \\
\hline Impuesto sobre Importación & $x$ & $\mathrm{x}$ & $x$ & $\mathrm{x}$ & $x$ & $x$ & $x$ \\
\hline Impuesto sobre Exportación & & & & & $x$ & $x$ & $x$ \\
\hline Derecho de entrada, salida y estadía de navíos & $x$ & & & & & & \\
\hline Tasa de correos y telégrafos federales & $\mathrm{x}$ & & & & & & \\
\hline $\begin{array}{r}\text { Tasas telegráficas, postales y de otros servicios federales de } \\
\text { entrada, salida y estadía de navíos y aeronaves }\end{array}$ & & $\mathrm{x}$ & $\mathrm{x}$ & & & & \\
\hline Impuesto de Consumo, excepto combustibles & & $x$ & & & & & \\
\hline Impuesto de Consumo de cualquier mercancía & & & $x$ & $x$ & & & \\
\hline Impuesto a la Renta, excepto sobre renta cedular de inmuebles & & $x$ & & & & & \\
\hline Impuesto a la Renta & & & $\mathrm{x}$ & $\mathrm{x}$ & $x$ & $x$ & $\mathrm{x}$ \\
\hline Impuesto sobre transferencia de fondos para el exterior & & $x$ & $x$ & $x$ & & & \\
\hline Impuesto sobre actos emanados de su gobierno & & $x$ & $x$ & $x$ & & & \\
\hline Impuestos en los territorios & & $\mathrm{x}$ & $\mathrm{x}$ & $x$ & $x$ & $x$ & \\
\hline Tasas de sello & $\mathrm{x}$ & & & & & & \\
\hline $\begin{array}{r}\text { Impuesto único sobre lubricantes y combustibles, minerales y } \\
\text { energía eléctrica }\end{array}$ & & & & $x$ & $x$ & $x$ & \\
\hline Contribución de mejoría & & & & $x$ & $x$ & $x$ & $x$ \\
\hline Tasas & & & & $x$ & $x$ & $x$ & $x$ \\
\hline Impuesto sobre propiedad rural & & & & & $\mathrm{x}$ & $\mathrm{x}$ & $x$ \\
\hline Impuesto sobre productos industrializados & & & & & $x$ & $x$ & $x$ \\
\hline Impuesto sobre operaciones de crédito, cambio y seguro (o relativo & & & & & $\mathrm{x}$ & $x$ & $\mathrm{x}$ \\
\hline Impuesto sobre servicios de comunicación y transportes & & & & & $\mathrm{x}$ & $x$ & \\
\hline Impuestos extraordinarios (guerra, etc.) & & & & $x$ & $\mathrm{x}$ & $x$ & $x$ \\
\hline Préstamos compulsorios & & & & $x$ & $x$ & $x$ & \\
\hline Impuesto sobre grandes fortunas & & & & & & & $x$ \\
\hline Otras (residual) & $\mathrm{x}$ & $\mathrm{x}$ & $x$ & $\mathrm{x}$ & $\mathrm{x}$ & $x$ & $x$ \\
\hline \multicolumn{8}{|l|}{ De las Provincias } \\
\hline Impuesto sobre Exportación & $x$ & $x$ & $\mathrm{x}$ & $x$ & & & \\
\hline Impuesto sobre inmuebles rurales y urbanos & $x$ & & & & & & \\
\hline Impuesto sobre trasmisión de propiedad & $x$ & & & & & & \\
\hline Impuesto sobre industrias y profesiones & $\mathrm{x}$ & $\mathrm{x}$ & $\mathrm{x}$ & & & & \\
\hline Impuestos sobre actos emanados de su gobierno & $x$ & $\mathrm{x}$ & $x$ & $x$ & & & \\
\hline Contribución sobre telégrafos y correos provinciales & $\mathrm{x}$ & & & & & & \\
\hline Impuesto sobre propiedad territorial excepto urbana & & $x$ & $\mathrm{x}$ & $x$ & & & \\
\hline Impuesto sobre propiedad territorial, causa mortis & & $\mathrm{x}$ & $x$ & $x$ & $x$ & $\mathrm{x}$ & $x$ \\
\hline Impuesto sobre trasmisión de propiedad inmobiliaria ínter vivos & & $x$ & $\mathrm{x}$ & $x$ & $x$ & $x$ & \\
\hline Impuesto sobre consumo de combustibles de motor a explosión & & $x$ & & & & & \\
\hline Impuesto sobre ventas y consignaciones & & $x$ & $x$ & $x$ & & & \\
\hline Impuesto sobre circulación de mercancías & & & & & $x$ & $x$ & $\mathrm{x}$ \\
\hline Tasa de servicios provinciales & & $\mathrm{x}$ & $\mathrm{x}$ & $\mathrm{x}$ & $\mathrm{x}$ & $\mathrm{x}$ & $\mathrm{x}$ \\
\hline Contribución de mejorías & & & & $x$ & $x$ & $\mathrm{x}$ & $\mathrm{x}$ \\
\hline Impuesto sobre propiedad de vehículos automotores & & & & & & & $x$ \\
\hline Adicional sobre impuesto a la renta e ingresos de cualquier tipo. & & & & & & & $x$ \\
\hline Otras (residual) & $x$ & $\mathrm{x}$ & $\mathrm{x}$ & $\mathrm{x}$ & $\mathrm{x}$ & $\mathrm{x}$ & $\mathrm{x}$ \\
\hline \multicolumn{8}{|l|}{ De los Municipios } \\
\hline Impuesto de licencia & & $x$ & $x$ & $x$ & & & \\
\hline Impuesto predial y territorial urbano & & $x$ & $x$ & $x$ & $x$ & $x$ & $x$ \\
\hline Impuesto sobre diversiones públicas & & $\mathrm{x}$ & $\mathrm{x}$ & $x$ & & & \\
\hline Impuesto cedular sobre renta de inmuebles rurales & & $\mathrm{x}$ & & & & & \\
\hline Impuesto sobre industrias y profesiones & & & & $x$ & & & \\
\hline Impuestos sobre actos de su economía & & & & $x$ & & & \\
\hline Impuestos sobre servicios de cualquier tipo & & & & & $x$ & $x$ & $x$ \\
\hline Tasas sobre servicios municipales & & $\mathrm{x}$ & $\mathrm{x}$ & $\mathrm{x}$ & $\mathrm{x}$ & $x$ & $\mathrm{x}$ \\
\hline Contribución de mejoría & & & & $x$ & $\mathrm{x}$ & $\mathrm{x}$ & $x$ \\
\hline Impuesto sobre trasmisión de propiedad inmobiliaria inter vivos & & & & & & & $x$ \\
\hline Impuesto sobre ventas minoristas de combustible líquido y & & & & & & & $x$ \\
\hline Otras (residual) & & & & $x$ & $x$ & $x$ & $\mathrm{x}$ \\
\hline
\end{tabular}

Fuente: basado en Silva \& Beres (1990), revisado y actuaizado por el autor. 
La experiencia de la Primera República se revierte después de la Revolución de 1930. En realidad, la entrada en escena de las ideas como del aumento del papel del Estado en la industrialización y de modernización del país, acaba por reforzar las reivindicaciones centralistas. En este período, se privilegia la desconcentración administrativa en lugar de la descentralización fiscal. No obstante, la Constitución de 1934 define con más claridad la atribución de los tributos, especialmente de los municipios, que pasan a tener derecho constitucional exclusivo de tributación sobre diversiones públicas. Pasan, también, a tener el derecho de cobrar el impuesto predial y territorial urbano, ${ }^{24} \mathrm{y}$ un impuesto sobre la renta de inmuebles rurales.

En la Constitución también aparecieron las tasas sobre servicios urbanos. Las Provincias pasaron a tener derecho constitucional exclusivo sobre la venta y consignaciones ${ }^{25}$, sobre el consumo de combustibles de vehículos a explosión, además de tasas sobre servicios provinciales. ${ }^{26}$ Los impuestos sobre el consumo y la renta ${ }^{27}$ se destinaron constitucionalmente a la Unión, al lado del impuesto de importación ${ }^{28}$. Se añadieron a éstos un impuesto sobre transferencia de fondos al exterior.

Desde el punto de vista de la estructura federativa, si por un lado se profundizó el modelo de separación de tributos con los nuevos impuestos, por otro lado, se introdujieron dos innovaciones. La primera, fue la distribución del recaudo entre diferentes esferas. El impuesto sobre industrias y profesiones, lanzado por las Provincias, pero su recaudación fueron igualmente dividida entre provincias y municipios. ${ }^{29}$ En segundo lugar, constitucionalmente se definieron normas sobre los impuestos de exportación provincial; que no podrían recaer sobre la exportación interprovincial que no podrían exceder el $10 \%$.

La Constitución de 1937 implicó cierta centralización, las Provincias perdieron los derechos de cobrar el impuesto por el consumo de combustibles de motor a explosión y los

\footnotetext{
${ }^{24} \mathrm{El}$ antiguo impuesto sobre inmuebles rurales y urbano de la constitución de 1891 se desmembró en dos: uno sobre propiedad territorial (excepto urbana) de carácter provincial y otro, predial y territorial urbano, de carácter municipal. ${ }^{25}$ Nombre que pasó a recibir el impuesto, creado en 1922, sobre ventas mercantiles.

${ }^{26}$ Cabía todavía a las Provincias, los impuestos sobre transacción, ahora divididos en Intervivos y causa mortis, además del ya mencionado impuesto sobre propiedad territorial, excepto la urbana.

${ }^{27}$ El impuesto sobre consumo, excepto consumo de combustibles y el impuesto a la renta.

${ }^{28}$ Además de las antiguas tasas telegráficas y sobre entrada, salida y estancia de navíos, añadían ahora el de las aeronaves.

${ }^{29}$ También para los nuevos tributos que la Provincias creasen, su recaudación debería dividirse con la Unión (un $30 \%$ ) y los municipios (un 20\%).
} 
municipios el ingreso de propiedades rurales, los dos transferidos a la Unión. Durante la Segunda Guerra Mundial les fue prohibido a las Provincias colectar impuestos sobre combustibles y lubricantes líquidos y sobre carbón mineral, que pasan a ser de incumbencia privada de la Unión. En este período, bajo la gestión de Getúlio Vargas, se estableció el aumento de los impuestos basados en factores internos al país, como el impuesto sobre consumo y el impuesto de renta, de orden federal. El impuesto sobre el consumo pasó a ser el principal impuesto federal en el país. ${ }^{30}$ En las Provincias también un impuesto interno, el impuesto de ventas y consignaciones, se convirtió en el principal impuesto provincial debido a los cambios en el impuesto de exportación. $^{31}$

Después de la Segunda Guerra Mundial se inició una época de descentralización. La Constitución de 1946 transfirió el impuesto sobre industrias y profesiones del ámbito provincial para el municipal, reforzando los ingresos de estas instancias administrativas. En la Unión, solamente se ratificaron los cambio realizados durante la Guerra, o sea, la creación de un impuesto sobre lubrificantes, combustibles, minerales y energía eléctrica. También, resultó significativo la introducción en la Constitución de la posibilidad de incrementar la recaudación a través de préstamos compulsorios (de pago obligatorio) e impuestos extraordinarios (guerra etc.).

Sin embargo, el cambio importante en la Constitución de 1946 fue la introducción de un sistema de transferencias definidas. La Unión se vio obligado a transferir como mínimo el $60 \%$ del impuesto sobre combustibles, lubricantes, energía eléctrica y minerales, además del $10 \%$ del impuesto de renta, para los municipios no capitales de Provincia. ${ }^{32}$ Los municipios pasaron también a tener el derecho de recibir recursos de las provincias. Las Provincias, en 1948 pasaron a tener el derecho a un $48 \%$ del impuesto nacional sobre combustibles, lubricantes, energía eléctrica y minerales. ${ }^{33}$ Estas transferencias fueron, en parte, condicionadas pues debieron

\footnotetext{
${ }^{30}$ Los impuestos internos se convirtieron en las principales fuentes recaudadoras de la Unión, a partir de la II Guerra Mundial. Si tomáramos el año 1945, notaremos que el impuesto de importaciones significaron solamente un 11,59\% de la recaudación federal, el impuesto sobre el consumo el 33,12\% y sobre los ingresos un 21,19\%.

${ }^{31}$ El impuesto sobre ventas y consignaciones representó durante la segunda guerra un $29,96 \%$ de lo recaudado por las provincias, mientras que el impuesto de exportación representó solamente un 3,36\%. El impuesto de transacción representó un $1,84 \%$ y sobre las industrias y profesiones un $5,44 \%$.

${ }^{32}$ En 1961 se aumentó para un $15 \%$ y sumó más un 10\% sobre el impuesto de consumo, pero ahora esta siendo transferido a todos los municipios.

${ }^{33}$ Los municipios en 1948 pasaron a tener una participación de $12 \%$ en recaudación.
} 
utilizarse en sistemas de transporte y desarrollo rural. ${ }^{34}$ Un problema con estas transferencias fue su efectiva realización y acababan erosionadas por la inflación en función de los plazos para el pasaje de los recursos. ${ }^{35}$

Entre 1946 y el golpe militar de 1964 quedó ratificada la participación de los impuestos internos como principal fuente de recaudación, mientras que los impuestos sobre consumo alcanzaron más del 40\% de la recaudación federal en el primer quinquenio de la década del 60. Los impuestos de importación pasaron a ser cada vez más impuestos reguladores, sirviendo de instrumentos para las intenciones industrializantes de los gobernantes. ${ }^{36}$

El sistema tributario presentó varios problemas que ya se destacaron desde la década del 40 sin que, sin embargo, se logró alterar sustancialmente el sistema tributario vigente. Sólo después del golpe militar se puedo promover la esperada reforma. Las principales críticas sobre el sistema tributario fueron: i) la insuficiente generación de recursos, ante los gastos crecientes del Estado brasileño; ii) el elevado grado de encubrimiento con fraude del sistema; iii) las distorsiones provocadas por la acumulación de los tributos incidentes en cascada, como por ejemplo, el elevado incentivo a la verticalización de las empresas; iv) las distorsiones derivadas del impacto de la inflación. Entre éstas podemos destacar: la tendencia al "olvido" del pago de impuestos, ya que los valores de las deudas no eran actualizados; los problemas que tienen origen de la variación del valor nominal de los inmuebles y otros activos, cuyo componente correspondiente a la corrección monetaria era considerado y tasado como lucro; las dificultades con impuestos como los prediales en función de la ausencia de corrección de los valores sobre los cuales recaían las alícuotas.

La dictadura militar impuso una fuerte reforma al sistema (1966-1967). Las modificaciones fueron:

\footnotetext{
${ }^{34}$ Un problema interesante relacionado a este último tipo de transferencias era la cuestión de la creación de municipios, incentivada por el hecho de que el conjunto total de los ingresos era distribuido por igual entre los municipios. Entre 1945 y 1966 creció más del doble, el número de municipios en Brasil, que pasaron de 1669 para 3924. De esta forma hubo una reducción del ingreso recibido de forma individual por los municipios debido a la ampliación de su número. A pesar de esto, algunos de los nuevos municipios vivieron casi exclusivamente de estos ingresos.

${ }^{35}$ Las transferencias de la Unión sobre el impuesto sobre los ingresos (renta) y sobre el de consumo se calculó en un año, con base en el año anterior, para pagarlas solamente el año siguiente.

${ }^{36}$ En las Provincias los impuestos sobre ventas y consignaciones responden por más de la mitad de la recaudación.
} 
a) eliminación de la tributación de lucros ilusorios, con la corrección monetaria de los balances y actualización de los valores de los débitos fiscales;

b) sustitución de los impuestos en cascada por impuestos sobre valor agregado, con el cambio del impuesto de consumo por el impuesto sobre productos industrializados (IPI) y del impuesto sobre ventas y consignaciones por el impuesto sobre circulación de mercancías (ICM) y la creación del Impuesto sobre Operaciones Financieras (IOF),

c) introducción de incentivos fiscales: exportación, mercado de capitales, regiones (SUDENE, SUDAM ${ }^{37}$ ), programas específicos (forestación, pesca etc.);

d) eliminación de la autonomía de las provincias y municipios en la definición de las respectivas reglas tributarias y la creación de los Fondos de Participación de Provincias y Municipios.

Esta reforma tributaria presentó algunas consecuencias importantes, como:

a) modernización del sistema, pues el país fue uno de los primeros del mundo en implantar efectivamente un sistema de valor agregado en la tributación sobre el consumo. ${ }^{38}$ La introducción de técnicas de actualización monetaria también se constituyó en una innovación bastante importante, así como la instrumentalización del sistema tributario (incentivos) para servir como política de promoción del desarrollo;

b) regresividad del sistema; ésta se hizo sentir en la alta participación de los impuestos indirectos $^{39}$ y en la enorme gama de incentivos fiscales;

c) centralización en el ingreso. Incluso el hecho del ICM ser de ámbito provincial, contrariando a la mayor parte de los analistas, el poder de legislación de las provincias sobre este impuesto era, en principio, reducido. ${ }^{40}$ Para compensar la centralización se crearon los fondos de participación, estableciendo el sistema de transferencia del gobierno central para los entes subnacionales;

${ }^{37}$ SUDENE: Superintendencia de Desenvolvimento do Nordeste, SUDAM: Superintendencia de Desenvolvimento da Amazonia

${ }^{38}$ Sólo Francia utilizaba un sistema semejante, pero nacional.

${ }^{39}$ Sobre la regresividad del sistema que en esencia no se alteró hasta los días de hoy ver Vianna (2000).

${ }^{40}$ Los problemas de un impuesto sobre el valor agregado provincial generaron la necesidad de crear en 1975 el CONFAZ - Consejo de los Secretarios Provinciales de la Hacienda. Sobre esto ver Bordin \& Langemann (1993). 
d) ampliación rápida del volumen de recaudación posterior a la reforma contribuyendo a revertir la tendencia al déficit público (gráfico 1).

Después de la reforma tributaria, el sistema poco a poco comenzó a presentar señales de deterioro. Especialmente en la década de los 80 se notaron algunas tendencias que permanecieron válidas en los años 90, éstas fueron: i) disminución de la capacidad de recaudación en función de la proliferación de los incentivos fiscales; ii) deterioro de la calidad del sistema en función de nuevos tributos y desgaste del IPI e ICM; iii) la descentralización, especialmente por medio de la ampliación de las transferencias (gráfico 2). ${ }^{41}$

\section{Gráfico 1}

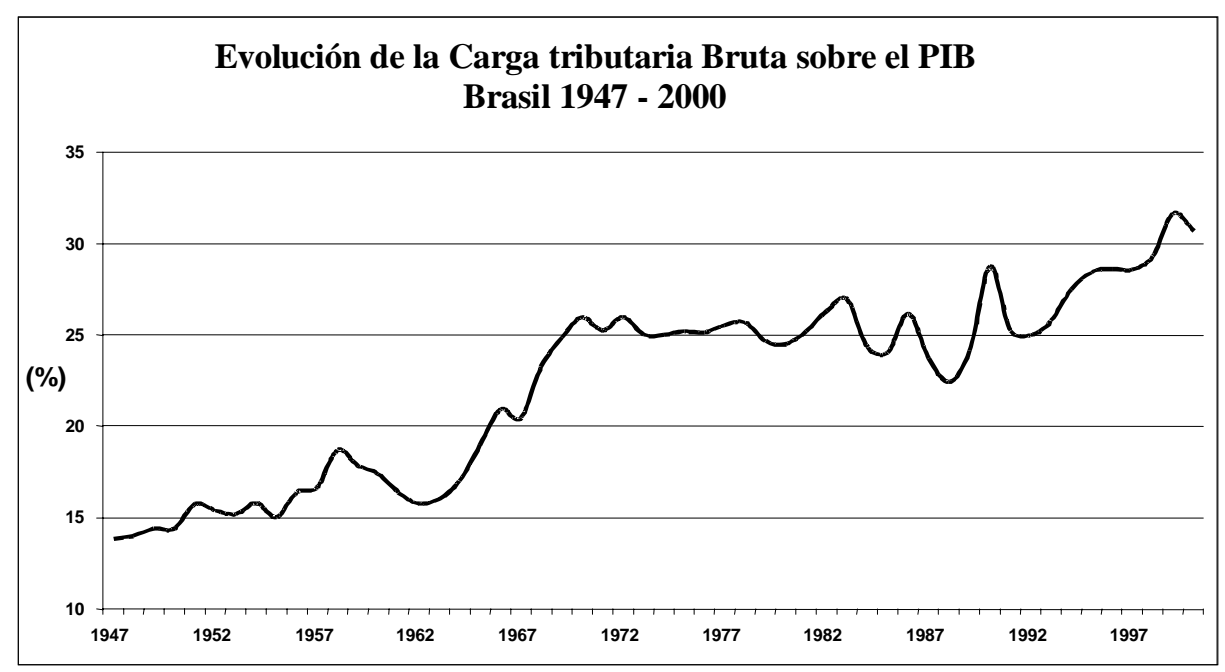

\footnotetext{
${ }^{41}$ Es importante destacar que el período estuvo marcado por una gran inestabilidad debido a los seguidos intentos de combate a la inflación, además por ser también un período marcado por la recesión económica.
} 


\section{Gráfico 2}

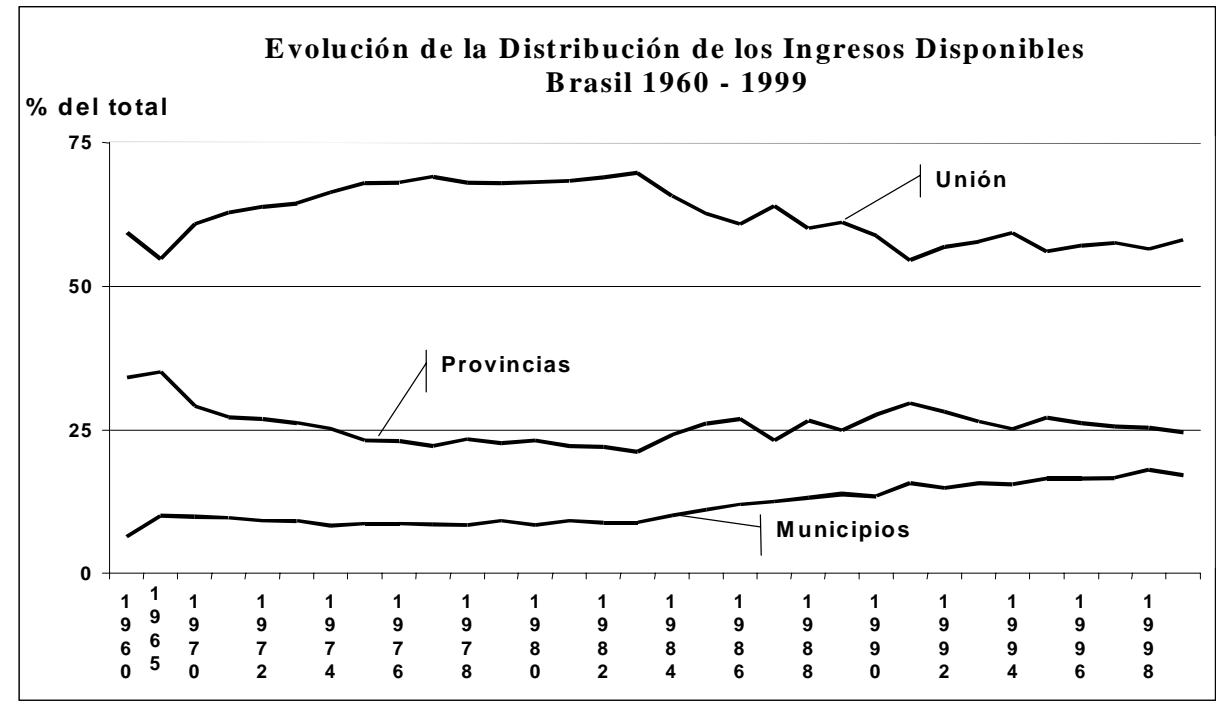

La descentralización que ocurrió en Brasil en los años 80 acompañó otros dos movimientos de la sociedad brasileña: el de la redemocratización y el de la pérdida de capacidad instrumental y financiera del Estado nacional. La Constitución de 1988 jugó un papel significativo en esta fase de descentralización. En ésta se admitió el federalismo pues se reconoció a la Unión, las Provincias e inclusive a los Municipios como entes constitutivos de la Federación. ${ }^{42}$ Así, formalmente el federalismo brasileño pudo considerarse bien estructurado, pues al contrario de concebir las parcelas subnacionales, como órganos desconcentrados de instancias superiores, especialmente los gobiernos locales, ubicaron a los tres niveles en igualdad política.

La asignación de funciones se efectuó en una situación donde no existió la precisión necesaria sobre cuál fue efectivamente el papel del Estado ante la sociedad. Claramente se transito de un estado productor a un estado regulador, pero no estuvo definido cuál será el punto de equilibrio en este cambio. Esta situación instaló una dificultad adicional a la indefinición de las atribuciones de los diferentes niveles jerárquicos, que reflejó la propia falta de definición de las atribuciones del Estado brasileño como un todo.

\footnotetext{
${ }^{42}$ Sobre el texto de la Constitución y las finanzas públicas ver Affonso (1999) y Cunha (1995).
} 
Las dificultades desde el punto de vista de la atribución de responsabilidades de gastos en el texto constitucional, hicieron que la descentralización de funciones, que estuvieron en curso ocurrió con poco criterio, dificultando la posibilidad de que se obtuvieran los beneficios previstos en términos de calidad de los servicios. Estos beneficios, en realidad, se encontraron en ciertas regiones, mientras que en otras esto no ocurrió. Normalmente las mejores experiencias de descentralización ocurrieron en regiones donde la capacidad financiera de gobiernos subnacionales fue fuerte. El peligro de esta descentralización desordenada fue el refuerzo de las desigualdades regionales del país.

El esquema fiscal adoptado sigue los principios de la separacion de tributos y de redistribución de ingreso por transferencias. Desde el punto de vista de los ingresos, se observó su crecimiento en las entidades subnacionales, principalmente municipios. La cuestión de las transferencias fue particularmente importante y explicó el hecho de que los pequeños municipios recibieron más ingresos, en contraposición a los grandes y medianos, lo que causó problemas horizontales bastante serios. Por otro lado, se amplió la libertad de las Provincias sobre el $\mathrm{ICMS}^{43}$, que acabó por elegirse como una de las bases para la denominada "guerra fiscal" entre las Provincias en Brasil.

\section{Conclusión}

Al observar la evolución histórica del sistema tributario brasileño, a partir de la óptica de los sistemas de distribución de ingresos, notamos que la República se inicia con un sistema de separación tributaria y evoluciona ampliando su complejidad. Al sistema inicial se sobreponen elementos de los sistemas centralizados, como la división de competencias tributarias y las transferencias. Prácticamente no se aplicaran elementos de los sistemas intermediarios. El único elemento que se encuentra en esta evolución, en la Constitución de 1988, es la posibilidad aportada a las Provincias de introducir un adicional al impuesto de renta, prácticamente no utilizado.

Esta constatación denota la tendencia centralizadora de la historia de la estructura federativa brasileña en el siglo XX. Una estructura descentralizada de tonalidades no

\footnotetext{
${ }^{43}$ Inclusive con la pérdida de capacidad de coordinación y harmonización del CONFAZ.
} 
competitivas y sí cooperativas, rigurosamente, nunca se instauró en Brasil; por lo menos desde el punto de vista de la estructura de distribución de las recaudaciones definidas constitucionalmente.

Tal vez, avanzar en este sentido pueda ser una alternativa razonable para la histórica indefinición brasileña, con respecto a sus relaciones intergubernamentales. Así, podría buscarse en Brasil la modificación de algunos impuestos, introduciendo la "co-responsabilidad" política, principalmente en el caso de impuestos sobre valor agregado e de renta. Realmente, las propuestas de la comisión de reforma tributaria del Congreso Nacional apuntaban, de cierta forma, en esta dirección en el caso de la reforma del ICMS/IPI, y existe constitucionalmente la posibilidad de avanzar en el impuesto de renta.

Obviamente, es necesario resaltar algunas cuestiones. Como afirmamos a lo largo del texto, los sistemas intermediarios presentan problemas con la redistribución horizontal de recursos y permiten, por ejemplo, la continuidad de la guerra fiscal, aunque en menor grado de que en la práctica actual. De este modo, la estructura del sistema debería minimizar estos problemas. Además, el sistema de transferencias no puede ser extinto, pero debe modificarse.

Con relación a la guerra fiscal, la alteración propuesta por la comisión mencionada anteriormente, de incidencia de los impuestos sobre el valor agregado del origen para el destino, es importante. Ampliar las reglas de responsabilidad por actos de los gobernantes y profundizar el sistema democrático, con la ampliación de prácticas fiscales participativas, también parece fundamental. Un elemento, que podría acompañar estos cambios, es la revitalización, tal vez en otros términos, de estructuras como el Consejo de los Secretarios Provinciales de la Hacienda. Instancias como el CONFAZ son importantes en la estructuración institucional de un federalismo cooperativo. Las formas de acción de estas instancias deberían promover la búsqueda de un sistema federativo más armonioso y justo.

\section{Bibliografía}

AFFONSO, J. R. R. Memória da Assembléia Nacional Constituinte: de 1987/88: As Finanças Públicas. Revista do BNDES, Vol. 11, jun., 1999. 
AFFONSO, J.R.R. \& T. Lobo. Descentralização Fiscal e Participação em Experiências Democráticas Retardatárias. Planejamento e Políticas Públicas, n. ${ }^{\circ} 14$ dez.

AFFONSO, R. \& P. Silva. A Federação em Perspectiva: Ensaios Selecionados. São Paulo, FUNDAP, 1995.

AMED, F.J. \& P.J.L.C. Negreiros. História dos Tributos no Brasil, São Paulo, SINAFRESP. 2000.

BAHL, R. W. Descentralização Fiscal: Uma Perspectiva Mundial: Cadernos de Finanças Públicas. ESAF, ano II, n. ${ }^{\circ} 1,2001$.

BIRD, R. Rethinking Subnational Taxes: A New Look at Tax Assignment. IMF Working Paper, October, 1999.

BORDIN, L.C. \& E. Lagemann. Harmonização Tributária: A Experiência Brasileira e o CONFAZ. Secretaria Estadual da Fazenda, Porto Alegre, 1995.

BURKI, S.J.; Perry, G.E. \& W.R. Dillinger. Beyond the Center: Descetralizing the State World Bank. Washington, 1999.

CARVAlHO, J. M. Teatro de Sombras: A Política Imperial. São Paulo: Vértice, Ed. Revista dos Tribunais; Rio de Janeiro, IUPERJ. 1988.

Federalismo y Centralización en el Imperio Brasileño: Historia $y$ Argumento. In: CARAMAGNANI, M. (org.) Federalismos Latinoamericanos: México/Brasil/Argentina, El Colegio de México / Fondo de Cultura Económica. México, 1993.

CUNHA, A. Grupos de Interesse e Blocos Regionais na Elaboração do Capítulo Tributário na Constituinte de 1987/1988, Dissertação de mestrado, UNB, Brasília, 1995.

DEVEZA, G. Política Tributária no Período Imperial. In: História Geral da Civilização Brasileira. Difel, Vol II tomo 4. São Paulo, 1995.

GREMAUD, A. P. Descentralização na América Latina: Benefícios, Armadilhas e Requisitos. Cadernos de Finanças Públicas ESAF, Vol. II (1). 2001.

KUGELMAS, E. \& L. Sola "Recentralização/Descentralização: dinâmica do regime federativo no Brasil dos anos 90”, Tempo Social, Vol.11(2). 1999. 
MORAES, M. R. As Relações Intergovernamentais na República Federal da Alemanha: Uma Analise Econômico Institucional. Fundação Konrad Adenauer. São Paulo, 2001.

MUSGRAVE, R.A. and P.B. Musgrave. Public Finance, McGrawHill, 1973.

PRADO, S. \& C.E.G. Cavalcanti. A Guerra Fiscal no Brasil. FUNDAP/FAPESP, São Paulo; IPEA: Brasília, 2000.

SILVA, M.C. \& N.A. Beres. Finanças Públicas. In: IBGE Estatísticas Históricas do Brasil, IBGE, $2^{\text {a }}$ ed. Rio de Janeiro, 1990.

STEPAN, A. Para uma Nova Análise Comparativa do Federalismo e da Democracia: Federações que Restringem e Ampliam o Poder do Demos. Revista de Ciências Sociais, Vol. 42 (2), 1999

TER-MINASSIAN, T. Fiscal Federalism in Theory and Practice. IMF. Washington, 1997.

VARSANO, R. A Evolução do Sistema Tributário Brasileiro ao Longo do Século: Anotações e Reflexões para Futuras Reformas. Pesquisa e Planejamento Econômico, 27(1), 1997.

VIANNA, S.W. Carga Tributária Direta e Indireta sobre as Unidades Familiares no Brasil: Avaliação de sua Incidência nas Grandes Regiões Urbanas em 1996. Texto para Discussão IPEA, IPEA, n. ${ }^{\text {7 } 757 . ~ B r a s i ́ l i a, ~} 2000$.

VIOL, A.L. O fenômeno da Competição Tributária: Aspectos Teóricos e uma Análise do Caso Brasileiro. Ministério da Fazenda, mimeo, 2000. 